\title{
Interpreting outputs of agent-based models using abundance-occupancy relationships
}

\author{
Toke Thomas Høye ${ }^{\mathrm{a}, \mathrm{b}, *}$, Flemming Skov ${ }^{\mathrm{a}}$, Christopher John Topping a,b \\ a Department of Bioscience, Aarhus University, Grenåvej 14, DK-8410 Rønde, Denmark \\ ${ }^{\mathrm{b}}$ Centre for Integrated Population Ecology, Denmark
}

\section{A R T I C L E I N F O}

\section{Article history:}

Received 2 February 2011

Received in revised form 18 January 2012

Accepted 22 January 2012

\section{Keywords:}

ALMaSS

AOR-index

Habitat quality

Land use

Landscape fragmentation

Scenarios

Wildlife

\begin{abstract}
A B S T R A C T
Reliable assessments of how human activities affect wild populations are essential for effective natural resource management. Agent-based models provide a powerful tool for integration of multiple drivers of ecological systems, but selecting and interpreting their output is often challenging. Here, we develop an indicator (the AOR-index) based on the abundance-occupancy relationship to facilitate the interpretation of agent-based model outputs. The AOR-index is based on the distribution of individuals in the landscape translated into the number of individuals in each cell of a regular grid. The proportion of grid cells with at least one individual is used to quantify occupancy and the mean number of individuals in occupied cells is used to quantify abundance. The AOR-index is a two-dimensional index giving the relative change in abundance and occupancy in response to a scenario (e.g. a change in land use or climate). We systematically modify a digital version of a real landscape to produce a set of artificial landscapes differing only in the degree of landscape fragmentation. We test how these different landscapes affect the AOR-index of six model animal species in four different land use scenarios using an agent-based model framework (ALMaSS). Our results suggest that the AOR-index is a sensitive tool to demonstrate how different species respond to particular land-use scenarios. The bird and mammal species generally showed larger responses than the invertebrates and changes in abundance and occupancy were often of different magnitude. The different responses are caused by species-specific habitat requirements and dispersal abilities, but the importance of such life history traits depend on landscape structure. Hence, predictions of species-specific responses to land-use changes in terms of abundance and occupancy are greatly improved by incorporation in a model framework taking spatial and temporal dynamics into account. The AOR-index facilitates the evaluation of multiple scenarios and allows for multi-species assessments. Its use, however, still requires identified management goals in order to evaluate scenario responses.
\end{abstract}

(c) 2012 Elsevier Ltd. All rights reserved.

\section{Introduction}

Reliable assessments of how human activities affect wild populations are essential for effective natural resource management. A principal challenge in such assessments is to integrate the effects of multiple drivers (e.g. land use and climate change) that interact to affect habitat and populations through time. Natural resource management is increasingly applying models to identify optimal management actions under given circumstances (Franklin, 2010). However, in order for such models to be effective at informing stakeholders, the model outputs will have to be easily interpretable and sufficiently precise to allow prioritizing amongst multiple management options.

* Corresponding author at: Department of Bioscience, Aarhus University, Grenåvej 14, DK-8410 Rønde, Denmark. Tel.: +45 87158892.

E-mail address: toh@dmu.dk (T.T. Høye).
Land use affects both landscape structure and habitat quality and is probably the most important driver of change in abundance and occupancy of animal species in agricultural ecosystems (Scholefield et al., 2011). In many cases, it is clear whether a certain land use change will be beneficial or detrimental to a particular species, but not to what extent and how exactly it will affect populations. For instance, hedgerow removal will affect many bird species negatively. Hedgerows provide nesting habitat to some species (e.g. yellowhammer, Emberiza citrinella) and foraging habitat for others (e.g. wintering waxwings, Bombycilla garrulus), and a combination of both for yet other species (e.g. whitethroat, Sylvia communis). The extent to which each habitat type is used and for which purpose depends on the ecology of the individual species. In many cases, restoring one component of the habitat will only be beneficial to a species if other requirements are met at the same time (Brambilla and Rubolini, 2009). Model systems aimed at quantifying species-specific responses to land 
use changes need to be able to incorporate such different requirements.

Attempts to integrate multiple drivers in predictive modelling is increasingly resulting in the development of rather complex agentbased model systems e.g. ALMaSS (Topping et al., 2003), MORPH (Stillman, 2008), PATCH (McRae et al., 2008), and SODA (Bennett et al., 2009). Applications of agent-based modelling are developing rapidly in environmental science and aided by increased computational capacity are now able to handle simulations of complex systems (Grimm et al., 2005). At the same time, methodological advances have facilitated the development and testing of agent-based models (Grimm et al., 2006; Topping et al., 2010a,b). Agent-based models can simulate the spatio-temporal dynamics in the environment and compute individual responses to this variation. While the flexibility of such model systems is becoming widely recognized, interpreting their output is still challenging. Yet, clear communication of results from agent-based models is important for priority-setting amongst land use scenarios (Jepsen et al., 2005). A simple indicator describing the most important responses of simulated ecological systems to land-use scenarios could make agent-based models a much more accessible tool for policy makers.

One of the most important large-scale biodiversity patterns is the generally positive relationship between local population density and site occupancy, the abundance-occupancy relationship (AOR). A distinction is made between the interspecific AOR and the intraspecific AOR, where the former describes the relationship forming amongst multiple species and the latter describes changes in abundance and occupancy through time for single species (Gaston et al., 2000). Scenarios of population development can thus be quantified by the intraspecific AOR relating current to future conditions. Here, we develop the AOR-index based on the abundance-occupancy relationship. We demonstrate the usefulness of the AOR-index for interpreting outputs of agent-based models. We illustrate the complexity of the responses by highlighting the interactions between spatial and temporal drivers of population dynamics by applying the AOR-index to outputs of the agent-based model system the Animal, Landscape and Man Simulation System (ALMaSS). Importantly, we also demonstrate how this complexity can be captured by the AOR-index. The AOR-index provides an objective indicator for comparing species responses to land use scenarios, and thus provides a basis on which management alternatives can be evaluated.

\section{Material and methods}

\subsection{Model framework}

We used the ALMaSS model framework which integrates topography, vegetation development, management, and weather with mechanistic agent-based models of animal species incorporating individual behavioural and ecological processes (Topping et al., 2003). The system has two main components, the environment and the model species. The ALMaSS environment incorporates topography in a GIS map of habitat elements, with a resolution of $1 \mathrm{~m}^{2}$, allowing narrow habitat elements to be modelled accurately. Habitat is divided into more than 30 different classes including forests, buildings, roads and roadside verges, water features, hedges, field boundaries, and fields. The growth of associated vegetation responds to variation in weather and management, such as harvest or fertilizer application. All agricultural management practices are controlled by virtual farmers who determine the composition, cover and sequence of crops in their fields. Management plans determine the order and timing of agricultural field operations using probabilities, weather, and the history of past management decisions. The resulting simulation of spatial and temporal farm events provides information to the animal models. Other modelled human activities include cutting of roadside verges in summer. The model time-step is one day. Full documentation of the ALMaSS model as well as link to source code is available at www.almass.dk.

\subsection{Model species}

The ALMaSS model framework is implemented for six model animal species resembling six real-world species: a carabid beetle (Bembidion lampros) (Bilde and Topping, 2004), a sheet web spider (Erigone atra) (Thorbek and Topping, 2005), the grey partridge (Perdix perdix) (Topping et al., 2010a), the skylark (Alauda arvensis) (Topping and Odderskær, 2004), the European brown hare (Lepus europaeus) (Topping et al., 2010b) and the field vole (Microtus agrestis) (Dalkvist et al., 2009). These species were chosen because they are common in agricultural ecosystems and their ecology is well understood which allowed the construction of detailed behavioural rules in the species models. They are all either typically used in pesticide risk assessments for non-target organisms or considered to be species sensitive to agricultural management. In the model, each species is simulated separately and inter-specific relationships (e.g. predation) are represented by daily survival probabilities depending on local environment, age class and time of the year (Topping et al., 2003).

\subsection{The AOR-index}

The aim of developing the AOR-index was to provide a tool to interpret changes in both abundance and distribution across species to changes in landscape structure and composition as well as the abiotic environment. The AOR-index was derived from locations of individuals of a particular model species. The landscape was overlaid with a regular grid and the number of adult females in each grid cell was recorded on 1 July. Occupancy was quantified as the proportion of grid cells occupied by at least one adult female and abundance as the mean number of adult females in occupied grid cells. We used different sized grids for each model species to account for the differences in the spatial scale at which the species use the landscape. If the grid cell size is too small, abundance will approach one individual per grid cell and if the grid cell size is too large, all cells will be occupied. Hence, the AOR-index will have limited sensitivity to detect a change in abundance or occupancy with too small or too large grid cell sizes, respectively. The optimal grid cell size depends on the distribution of individuals of the particular species. We used three heuristic rules to identify the optimal grid cell size for each model species. Firstly, we calculated the proportion of occupied grid cells in the baseline landscape at grid cell sizes between $50 \mathrm{~m}$ and a grid cell size leading to at least 250 grid cells in total (Appendix A). Our landscape was $8 \mathrm{~km} \times 8 \mathrm{~km}$ leading to a maximal grid cell size of $500 \mathrm{~m}$. Secondly; we excluded all grid cell sizes where more than $50 \%$ of the cells were occupied. If this excluded all grid cell sizes we choose $50 \mathrm{~m}$ as the grid cell size for the species. Thirdly, we calculated the mean density of individuals in all occupied grid cells and identified the species-specific scale as the grid cell size with a mean density closest to five individuals. The first rule was introduced to maintain resolution in the measure of occupancy to allow small distributional changes to be detected. The second rule ensured that both positive and negative changes in occupancy would be detected and the third rule ensured some variation in abundance. Without the last rule, abundance for territorial species would approach one female per grid cell and be insensitive to change. The resulting grid cell sizes were $50 \mathrm{~m}$ for the beetle and the spider, $100 \mathrm{~m}$ for the vole, $200 \mathrm{~m}$ for the skylark, and $400 \mathrm{~m}$ for the hare and the partridge. We ran each simulation for 60 years and discarded the first 10 years to allow the population 
A

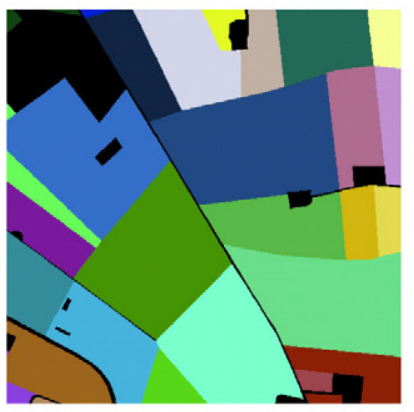

C

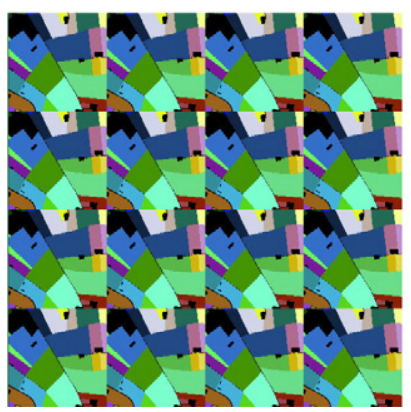

B

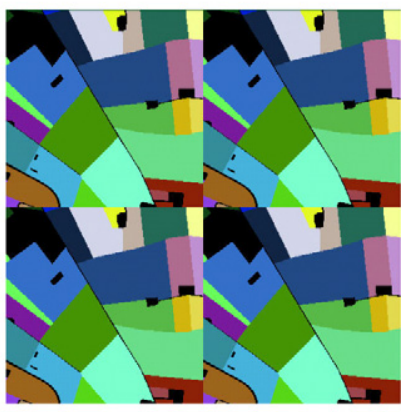

D

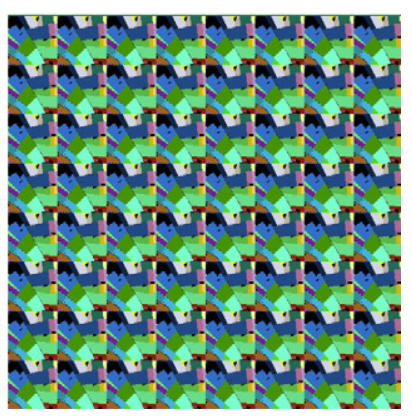

Fig. 1. Four $8 \mathrm{~km} \times 8 \mathrm{~km}$ artificial landscapes of increasing fragmentation from $A$ to D. Colours indicate fields managed identically. The areas of all fields and other habitats, management and vegetation growth is identical in all four landscapes, only the degree of fragmentation of the patches is altered. (For interpretation of the references to color in figure legend, the reader is referred to the web version of the article.)

to stabilize from a random initial distribution of individuals across the landscape. The AOR-index was derived from the mean value of abundance and occupancy across years.

\subsection{Landscapes and land use scenarios}

We developed four artificial landscapes and four land use scenarios with the aim of testing the sensitivity of the AOR-index to a diverse set of conditions for the six model species. The landscapes were created from an orthophoto of a $1 \mathrm{~km} \times 1 \mathrm{~km}$ area in Denmark. All four landscapes were $8 \mathrm{~km} \times 8 \mathrm{~km}$, the first (A) being a scaled up version of the $1 \mathrm{~km} \times 1 \mathrm{~km}$ area, the second (B) formed of four identical $4 \mathrm{~km} \times 4 \mathrm{~km}$ areas scaled in the same way as A, the third (C) formed of 16 identical $2 \mathrm{~km} \times 2 \mathrm{~km}$ areas scaled in the same way as $A$, and the last (D) formed of 64 copies of the original $1 \mathrm{~km} \times 1 \mathrm{~km}$ area (Fig. 1). This procedure ensured that the location of habitat patches varied amongst the landscapes with increasing fragmentation from landscape A to landscape D while keeping the area cover of each habitat type constant. Management carried out in one field in the least fragmented landscape is carried out simultaneously in 64 fields in the most fragmented landscape.

We developed four different land use scenarios and tested the response of all six model animal species to these scenarios. The scenarios were developed to produce a range of different responses in the six model species by changing the landscape type of existing polygons rather than drawing entirely new maps, hence the unusual \% change. In the FOREST scenario, $19.86 \%$ of the area was changed from arable land to deciduous forest. In the HEDGE scenario, $0.28 \%$ of the area was changed from field boundary to hedge rows. In the PASTURE scenario, $19.86 \%$ of the area was changed from arable land to permanent pasture. In the CROP scenario, the crop diversity was reduced to two crop types, an under-sown spring barley, and 1st year grazed clover grass sward, resembling the crop composition in areas of intensive dairy production (Topping, 2011).

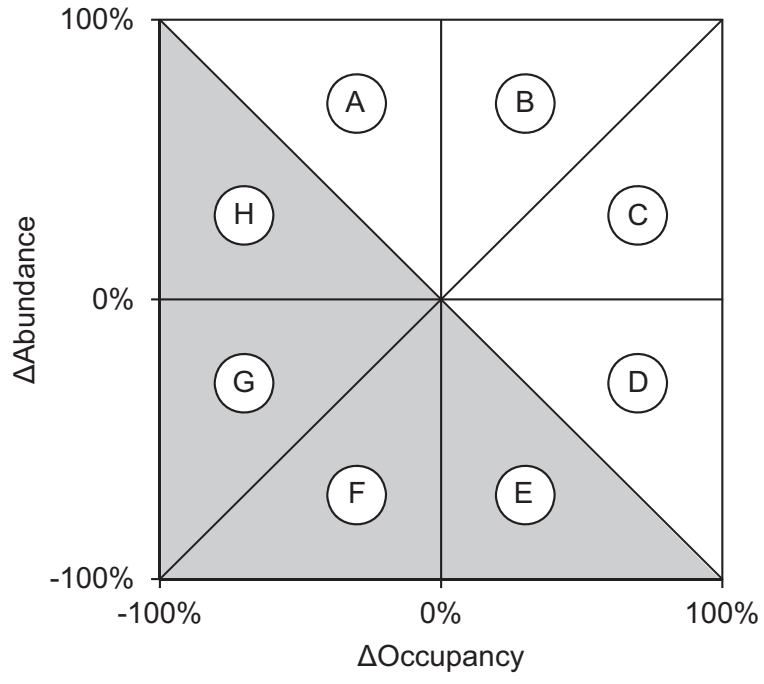

Fig. 2. The AOR-index is defined by the change in abundance and occupancy between a baseline and a scenario. If the AOR-index falls within segments A-D, population size is increasing and within segments $\mathrm{E}-\mathrm{H}$ (shaded) the population size is decreasing. Changes directly along the $y$-axis indicate improvement or degradation of habitat quality and changes along the $x$-axis indicate a change in the amount of habitat. See text for full explanation.

All other scenarios used a diverse crop rotation based on ten different crops with different proportions of area coverage (Appendix A). We ran 10 replicates of each land use scenario for each landscape for each species and calculated the AOR-index from mean values of abundance and occupancy across replicates.

\section{Results}

\subsection{Interpreting the AOR-index}

The AOR-index is represented by the change in abundance and occupancy of a species in a given scenario compared to a baseline. The two dimensions of the AOR-index can be plotted as a scatterplot with the axes ranging from $-100 \%$ to $\infty$ (Fig. 2). The index has a number of useful properties. If the AOR-index falls within segments A-D, population size is increasing, while it is decreasing within segments E-G. The greatest increase or decrease in population size is found along the $45^{\circ}$ line $(-100 \% ;-100 \%)$ to $(\infty ; \infty)$. If occupied grid cells are regarded as habitat and the abundance of individuals in a given grid cell as indicative of the habitat quality, a number of additional interpretations are possible. Occupancy becomes a measure of the amount of habitat and abundance a measure of the mean quality of habitat. Hence, an AOR-index falling above the $x$-axis indicates an increase in habitat quality and an AOR-index below the $x$-axis indicates a decrease in habitat quality. Similarly, an AORindex falling to the right of the $y$-axis indicates an increase in the amount of habitat and an AOR-index left of the $y$-axis indicates a decrease in the amount of habitat. This means that in section A, F, $\mathrm{G} \& \mathrm{H}$ habitat is lost and the quality of the lost habitat decreases from $F$ via $G$ and $H$ to A. Similarly, habitat of decreasing quality is gained from $B$ via $C$ and $D$ to $E$. These interpretations describe the net changes. It is possible to have increases in habitat and habitat quality in one part of the landscape and decreases in both habitat and habitat quality in other parts of the landscape for all values of the AOR-index. The AOR-index reduces the complexity of the model results to a simple index, yet the resultant statistic can be used to evaluate a range of possible outcomes. An example of calculating abundance and occupancy for the AOR-index is given in Fig. 3. Below, we present a selection of the results from the scenarios. 
A

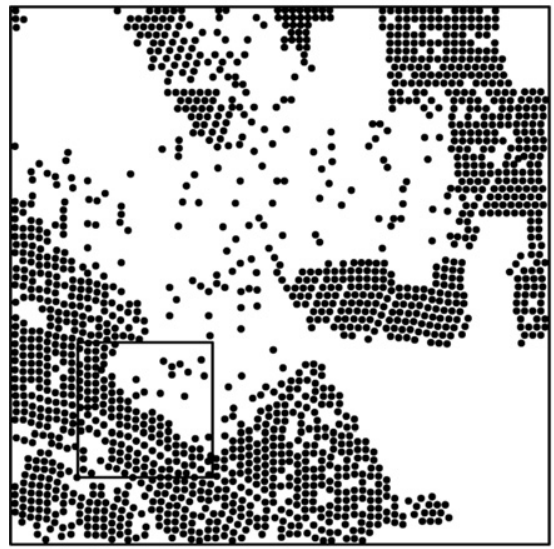

B

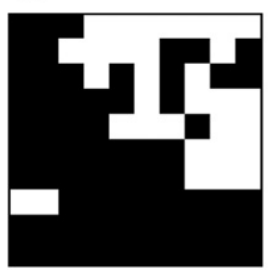

c

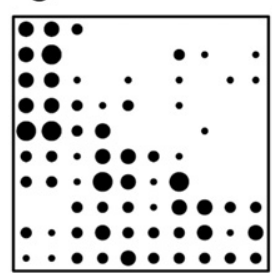

D

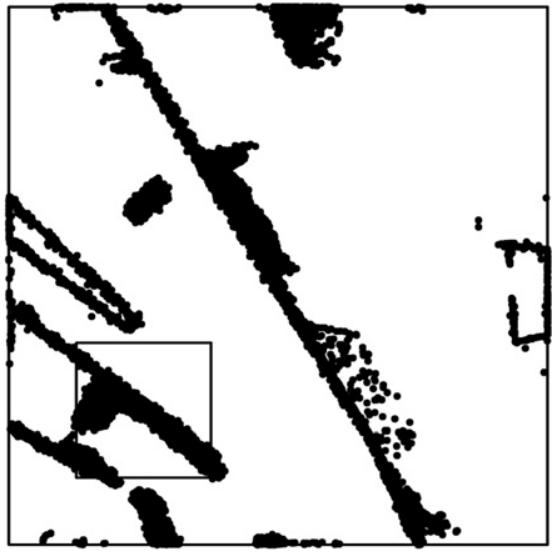

E

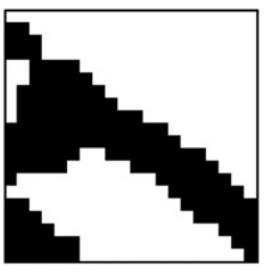

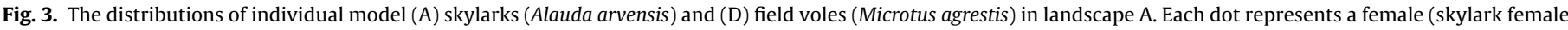

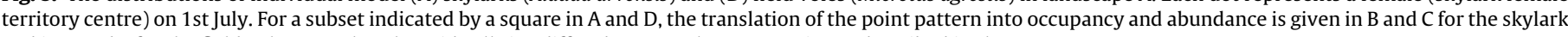
and in $\mathrm{E}$ and $\mathrm{F}$ for the field vole. Note that the grid cell size differs between the two species as described in the text.

\subsection{Model species responses to land use scenarios}

The six model species had very different distribution patterns exemplified by the skylark and the vole in Fig. 3. Each species responded differently to variation in the degree of landscape fragmentation. The skylark and the partridge were the only species to increase in occupancy in response to decreased landscape fragmentation and this response was transient in the partridge with reduced occupancy at low levels of landscape fragmentation. The skylark, partridge, vole and to a lesser extent the spider increased in abundance, while the hare and the beetle decreased both in terms of abundance and occupancy. As a consequence, overall population size was larger in three out of six species in the least fragmented landscape compared to the most fragmented landscape (Fig. 4).

Species responses to the four land use scenarios differed greatly both amongst species and scenarios (Fig. 5). Adding FOREST was negative for population size of all species, although abundance increased for beetle and skylark. For the other three scenarios (HEDGE, PASTURE and CROP), changes in abundance and occupancy were largely in the same direction except for the partridge and rarely of equal magnitude. The AOR-index for the partridge was generally in the opposite quadrant of the other species in these three scenarios (Fig. 5).

The effect of the land use scenarios interacted with the degree of landscape fragmentation, but not uniformly. For instance, the skylark was generally abundant and had the widest range in the least fragmented landscape in the FOREST and HEDGE scenario, but this trend was reversed in the PASTURE scenario, and particularly in the CROP scenario. Fig. 6 illustrates these responses by plotting change in abundance and occupancy for each of the four landscapes for each of the land use scenarios for the skylark, allowing trends and inconsistencies to be easily identified.
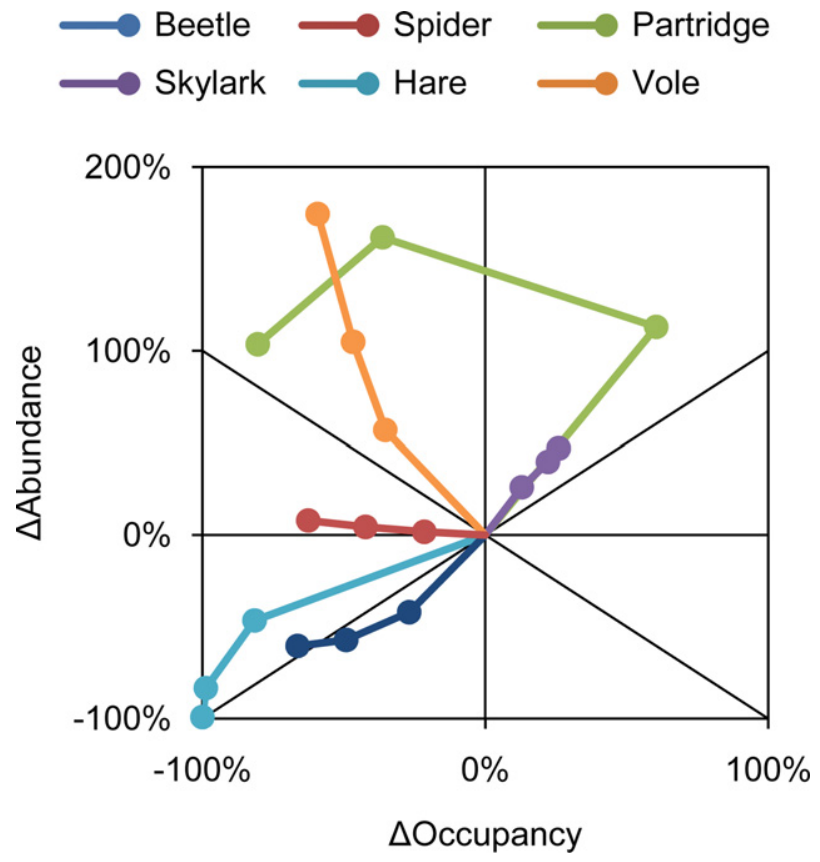

Fig. 4. The AOR-index plotted for six model animal species: a carabid beetle (Bembidion lampros), a sheet web spider (Erigone atra), grey partridge (Perdix perdix), skylark (Alauda arvensis), European brown hare (Lepus europaeus) and field vole (Microtus agrestis) in response to decreasing landscape fragmentation. The effect of landscape fragmentation is indexed by taking the difference in abundance and occupancy of landscapes A-C relative to landscape $\mathrm{D}$. The comparisons are connected in order of decreasing fragmentation starting with the comparison of landscape $C$ and D. 


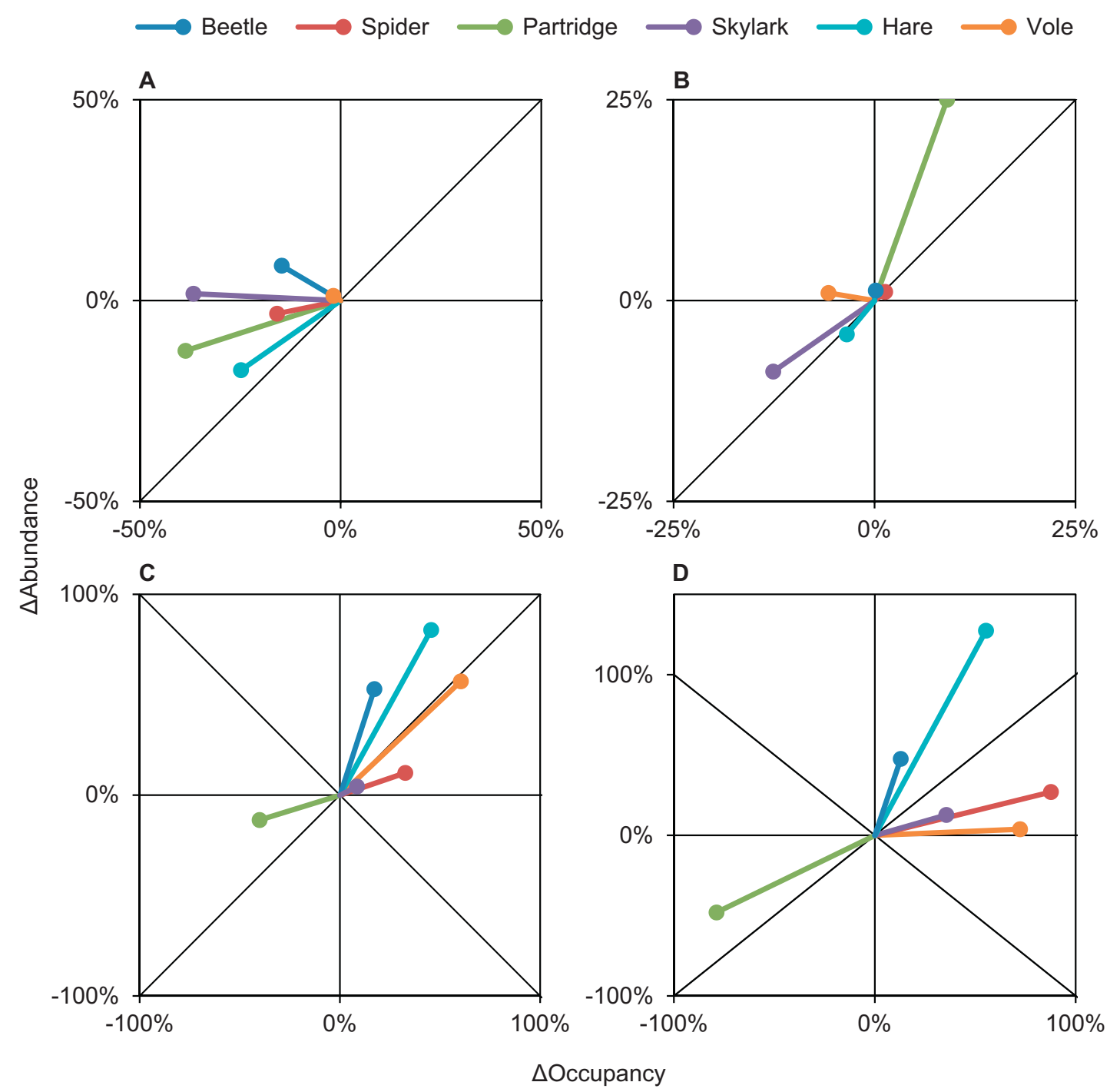

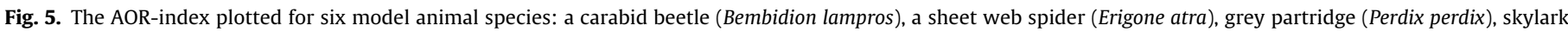

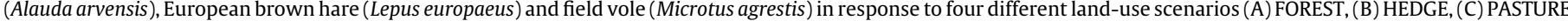
and (D) CROP in landscape D. In each species in each panel, the effect of the scenario is presented relative to the baseline.

\section{Discussion}

Agent-based modelling is increasingly being proposed as a means to predict the consequences of alternative land use scenarios and to identify optimal management solutions. A simple tool is needed to facilitate interpretation of such predictions for managers and policy-makers and with the AOR-index we have provided such a tool. The index is both simple to interpret and detailed enough to provide answers to the underlying nature of the difference between the baseline situation and a particular scenario. Although the AOR-index is generated for the entire landscape and may hide within landscape dynamics, it is a sensitive indicator of population changes. The responses of the model species to the example scenarios in terms of the AOR-index were easy to interpret and in the expected direction allowing us to conclude that the indicator is generally useful for agent-based modelling and the evaluation of land use scenarios. One possible alternative would be population viability analysis which is often regarded as the classical tool to evaluate population-level consequences of management actions for endangered species. In this respect, comparisons of mean time to extinction or intrinsic mean time to extinction are useful to estimate the persistence of populations subject to different environmental conditions (Grimm and Wissel, 2004). However, extracting the frequency distribution of time to extinction populations of abundant species simulated by complex agent-based models considering temporal changes in drivers dynamically would be computationally demanding and require much longer time than assessments based on the AORindex (Topping et al., 2010b). For instance, populations of the model species integrated in ALMaSS tend to be rather stable and will typically not die out at century-long time scales (Høye unpublished results). In such cases, time to extinction is a less useful metric to evaluate the effects of changes in e.g. land use or climate change than changes in abundance and occupancy as integrated in the AOR-index.

Our results add to existing efforts to separate the effects of habitat loss and habitat fragmentation (Smith et al., 2009). For example, interactions between landscape fragmentation and landuse in the skylark suggest that general conclusions about the effects of particular land-use changes are dependent on landscape context (Topping, 2011). The underlying cause of the increase in skylark numbers with landscape fragmentation was the temporal variation in food availability. With small fields, there was a higher diversity of vegetation types within the home range of the skylarks, and hence 


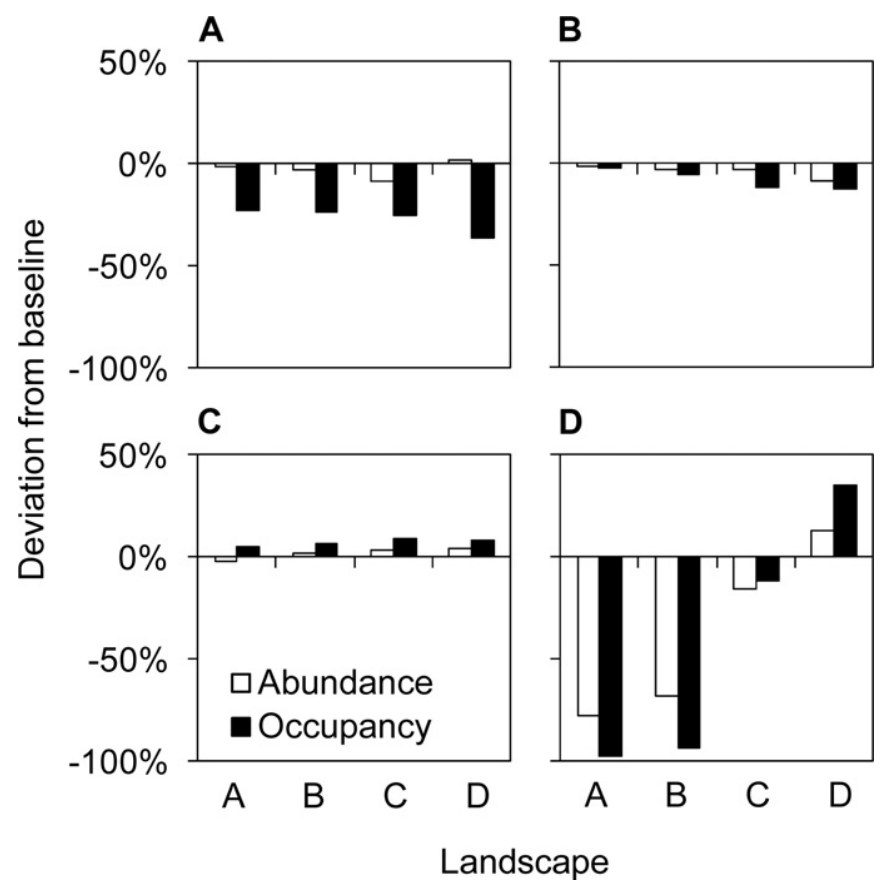

Fig. 6. Changes in abundance and occupancy with each of four land use scenarios (A) FOREST, (B) HEDGE, (C) PASTURE and (D) CROP and increasing landscape fragmentation from landscape $A$ to landscape $D$, relative to the appropriate landscape baseline for model skylarks (Alauda arvensis). Different responses amongst landscapes within the same scenario indicate an interaction between landscape and scenario. In the CROP scenario, the response in abundance and occupancy change from negative in landscape A-C to positive in landscape D.

better foraging opportunities for birds while incubating and raising chicks; but this is only the case, when a variety of crops are grown in the fields (Gevers et al., 2011; Topping and Odderskær, 2004), hence the reversal of the effect of landscape structure with the CROP scenario. Such effects can also be seen in real world studies. For instance Gabriel et al. (2010) showed how biodiversity depends on farming practices, but that there is a strong interaction with both fine and coarse scale variables.

Species respond to changes in habitat or landscape composition at different scales (Revilla and Wiegand, 2008). In many cases, landuse or landscape structural changes will affect both the number of individuals as well as their occupancy in the landscape. Positive abundance-occupancy relationships have been documented across a broad range of taxa in many habitats (Gaston et al., 2000). It is often assumed that occupancy and abundance respond similarly to landscape changes, but it has been difficult to demonstrate in the field for obvious practical reasons (Webb et al., 2007). Here, we have demonstrated that abundance and occupancy rarely change at the same rate in response to land use changes. Since, the AOR-index can be applied to any model capable of predicting the locations of individuals, the implementation of the AOR-index in agent-based model systems opens up for a range of future studies. There could be particular merit in a better understanding of how occupancy and abundance may vary temporally and spatial in differently structured landscapes.

The spatial scale at which a species respond most strongly to the amount of habitat has been described as the characteristic spatial scale of a species (Holland et al., 2004). Ideally, grid-based studies of occupancy and abundance should be studied at this species-specific grid cell size. While field data normally has insufficient resolution to allow for such decisions, it is possible to study data generated from agent-based model systems at different spatial scales. We outline criteria for selecting grid cell sizes that relate to the distribution of individuals in the particular baseline landscape. Hence, the underlying distribution of individuals should be checked in future applications of the AOR-index, and a suitable grid cell size chosen accordingly. For instance, in the case of the partridge at densities found in the 1950s, which were at least an order of magnitude higher than those simulated here (Blank et al., 1967), a smaller grid cell size may also have been suitable (Topping et al., 2010a). Nevertheless, the grid cell sizes we identified for the individual species in this study will probably be relevant across most landscapes where the species are found.

We argue that the AOR-index is a useful indicator for agentbased modelling and that it is particularly relevant for impact assessments. However, the AOR-index does not automatically define policy goals; it provides a tool to evaluate how species distribution and abundance would change under a given scenario. For example, in some contexts the field vole is a species of conservation concern, in others (e.g. orchard management) it can be a pest species. Determination of targets will therefore depend on the management context. For some management purposes, it could be relevant to combine the responses of individual species into one multi-species index. Importantly, the effect of changes in occupancy and abundance on population viability depends on the initial state of the population and the species in question. Hence, variation in responses across species should be subject to biological interpretation of how the scenario affects the requirements of the particular species. Similarly, if scenarios are tested for multiple baseline landscapes, any differences between landscapes should be checked against the population size and viability in each baseline landscape. In any case, a multi-species index could be based on equal weighting of the included species or could give priority to species based on e.g. particular indicator value, ecological characteristic or other criteria. These adaptations would be easily carried out by a policy manager since they require only arithmetic manipulation of the index. Once management goals have been identified it is possible to identify the most optimal management scenario as part of a multi-criteria decision analysis (Linkov et al., 2006; Triantaphyllou, 2000). The AOR-index can be a key element in such a cost-effective method for screening potential management or policy initiatives.

\section{Acknowledgements}

This project was carried out under joint funding from the Aarhus University Research Foundation, Miljøstyrelsens program for Bekæmpelsesmiddelforskning and the Refugia project funded by Research in Organic Food and Farming, International Research Co-operation and Organic Integrity (DARCOF III 2005-2010). Constructive comments from two anonymous reviewers considerably improved the manuscript.

\section{Appendix A. Supplementary data}

Supplementary data associated with this article can be found, in the online version, at doi:10.1016/j.ecolind.2012.01.017.

\section{References}

Bennett, V.J., Beard, M., Zollner, P.A., Fernández-Juricic, E., Westphal, L., LeBlanc, C.L., 2009. Understanding wildlife responses to human disturbance through simulation modelling: a management tool. Ecological Complexity 6, 113-134.

Bilde, T., Topping, C.J., 2004. Life history traits interact with landscape composition to influence population dynamics of a terrestrial arthropod: a simulation study. Ecoscience 11, 64-73.

Blank, T.H., Southwood, T.R.E., Cross, D.J., 1967. The ecology of the partridge I. Outline of population processes with particular reference to chick mortality and nest density. Journal of Animal Ecology 36, 549-556.

Brambilla, M., Rubolini, D., 2009. Intra-seasonal changes in distribution and habitat associations of a multi-brooded bird species: implications for conservation planning. Animal Conservation 12, 71-77. 
Dalkvist, T., Topping, C.J., Forbes, V.E., 2009. Population-level impacts of pesticideinduced chronic effects on individuals depends more on ecology than toxicology. Ecotoxicology and Environmental Safety 72, 1663-1672.

Franklin, J., 2010. Moving beyond static species distribution models in support of conservation biogeography. Diversity and Distributions 16, 321-330.

Gabriel, D., Sait, S.M., Hodgson, J.A., Schmutz, U., Kunin, W.E., Benton, T.G., 2010 Scale matters: the impact of organic farming on biodiversity at different spatial scales. Ecology Letters 13, 858-869.

Gaston, K.J., Blackburn, T.M., Greenwood, J.J.D., Gregory, R.D., Quinn, R.M., Lawton, J.H., 2000. Abundance-occupancy relationships. Journal of Applied Ecology 37, 39-59.

Gevers, J., Høye, T.T., Topping, C.J., Glemnitz, M., Schröder, B., 2011. Biodiversity and the mitigation of climate change through bioenergy: impacts of increased maize cultivation on farmland wildlife. Global Change Biology Bioenergy 3, $472-482$.

Grimm, V., Berger, U., Bastiansen, F., Eliassen, S., Ginot, V., Giske, J., Goss-Custard, J., Grand, T., Heinz, S.K., Huse, G., Huth, A., Jepsen, J.U., Jørgensen, C., Mooij, W.M., Müller, B., Pe'er, G., Piou, C., Railsback, S.F., Robbins, A.M., Robbins, M.M., Rossmanith, E., Rüger, N., Strand, E., Souissi, S., Stillman, R.A., Vabø, R., Visser, U., DeAngelis, D.L., 2006. A standard protocol for describing individual-based and agent-based models. Ecological Modelling 198, 115-126.

Grimm, V., Revilla, E., Berger, U., Jeltsch, F., Mooij, W.M., Railsback, S.F., Thulke H.H., Weiner, J., Wiegand, T., DeAngelis, D.L., 2005. Pattern-oriented modeling of agent-based complex systems: lessons from ecology. Science 310 987-991.

Grimm, V., Wissel, C., 2004. The intrinsic mean time to extinction: a unifying approach to analysing persistence and viability of populations. Oikos 105, 501-511.

Holland, J.D., Bert, D.G., Fahrig, L., 2004. Determining the spatial scale of species response to habitat. Bioscience 54, 227-233.

Jepsen, J.U., Topping, C.J., Odderskær, P., Andersen, P.N., 2005. Evaluating consequences of land-use strategies on wildlife populations using multiplespecies predictive scenarios. Agriculture, Ecosystems and Environment 105, 581-594.

Linkov, I., Satterstrom, F.K., Kiker, G., Batchelor, C., Bridges, T., Ferguson, E., 2006. From comparative risk assessment to multi-criteria decision analysis and adaptive management: recent developments and applications. Environment International 32, 1072-1093.
McRae, B.H., Schumaker, N.H., McKane, R.B., Busing, R.T., Solomon, A.M. Burdick, C.A., 2008. A multi-model framework for simulating wildlife population response to land-use and climate change. Ecological Modelling 219, 77-91.

Revilla, E., Wiegand, T., 2008. Individual movement behavior, matrix heterogeneity, and the dynamics of spatially structured populations. Proceedings of the National Academy of Sciences of the United States of America 105, 19120-19125.

Scholefield, P., Firbank, L., Butler, S., Norris, K., Jones, L.M., Petit, S., 2011. Modelling the European farmland bird indicator in response to forecast land-use change in Europe. Ecological Indicators 11, 46-51.

Smith, A.C., Koper, N., Francis, C.M., Fahrig, L., 2009. Confronting collinearity: comparing methods for disentangling the effects of habitat loss and fragmentation. Landscape Ecology 24, 1271-1285.

Stillman, R.A., 2008. MORPH - an individual-based model to predict the effect of environmental change on foraging animal populations. Ecological Modelling 216, 265-276.

Thorbek, P., Topping, C.J., 2005. The influence of landscape diversity and heterogeneity on spatial dynamcis of agrobiont linyphiid spiders: an individual-based model. Biocontrol 50,1-33.

Topping, C.J., 2011. Evaluation of wildlife management through organic farming. Ecological Engineering 37, 2009-2017.

Topping, C.J., Hansen, T.S., Jensen, T.S., Jepsen, J.U., Nikolajsen, F., Odderskær, P., 2003. ALMaSS, an agent-based model for animals in temperate European landscapes. Ecological Modelling 167, 65-82.

Topping, C.J., Høye, T.T., Odderskær, P., Aebischer, N.J., 2010a. A pattern-oriented modelling approach to simulating populations of grey partridge. Ecological Modelling 221, 729-737.

Topping, C.J., Høye, T.T., Olesen, C.R., 2010b. Opening the black box - development testing and documentation of a mechanistically rich agent-based model. Ecological Modelling 221, 245-255.

Topping, C.J., Odderskær, P., 2004. Modeling the influence of temporal and spatia factors on the assessment of impacts of pesticides on skylarks. Environmenta Toxicology and Chemistry 23, 509-520.

Triantaphyllou, E., 2000. Multi-criteria Decision Making Methods: A Comparative Study. Kluwer Academic Publishers.

Webb, T.J., Noble, D., Freckleton, R.P., 2007. Abundance-occupancy dynamics in a human dominated environment: linking interspecific and intraspecific trends in Briths farmland and woodland birds. Journal of Animal Ecology 76, 123-134 